\title{
Sustainable urban landscape
}

\author{
G. Aponte García \\ Universidad Pontificia Bolivariana, Colombia
}

\begin{abstract}
Landscape is more than a beautiful sight. Landscape is widely known as the integrated perception of the outdoors environment; this is to say, the awareness of the daily habitat, or the result of the interaction between natural forces and human activity. The purpose here is to point out how a wise understanding and managing of the landscape phenomena largely contributes to a sustainable city. An attitude towards nature that reduces it to seize the goodness of immediate material resources and waste disposal facilities, or to satisfy inconvenient alien aesthetics has led to a divorce between urban inhabitants and natural local processes and expressions. Therefore, society has been called to produce other kind of energy in order to replace or compensate the wasted natural one, with the delusion of being sustainable.

Since the progressive transformation of landscape may be perceived, lived and breathed by residents in urban settlements it might be valued, regulated and planned by them as well, providing a tangible and practical meaning of sustainability based on a sense of place. A considerable part of the professional work originated from the landscape thinking and knowledge can provide a significant contribution towards sustainability. The landscape line of thinking and practice is progressively gaining visibility in Colombia, the path is being built and some achievements about have been got through the Landscape Design Maser program at Universidad Pontificia Bolivariana. Next steps to follow in the local context are outlined as a conclusion.

Keywords: landscape contribution, urban landscape, sense of place, sustainable landscape.
\end{abstract}

\section{Introduction}

The late XX century and the beginning of the XXI are clearly signed by a rapid transformation in many areas. Due to its character of integral as a fact, and 
integrative as a purpose, landscape receives the impacts derived from the accelerated development and has the challenge of facing all sorts of transformations related to the building of the human habitat. Indeed, the concept as well has evolved since the time when it was closely related to -or even defined as- painting or gardening, hundreds of years ago, to its actual crucial and complex meaning and significant role in the present world as it has been highlighted by Jellicoe: "The world is moving into a phase when landscape design may well be recognized as the most comprehensive of the arts" [1].

As the result of several Latin American countries agreement on the matter, the Latin American Landscape Initiative (LALI) was formalized in 2012. It represents the regional support to the International Landscape Convention ILC, in development between UNESCO and the International Federation of Landscape Architects (IFLA). Among the numerous definitions of landscape, in this case it is appropriate to fundament this discussion in LALI's approach, because of its geographical and cultural coverage of application. It states that:

"The Landscape is defined as a space/time result of natural and human, tangible and intangible factors, that being perceived and shaped by the people, reflects the diversity of cultures" (LALI [2]).

It is recognized that landscape is not just a scene susceptible to be appreciated in a two-dimensional representation, but a three-dimensional space were we, perceptive human beings, are immerse as an integral part. The mention of the time factor, contributes to the spectrum bringing the idea of dynamics, evolution, and let suppose diverse speeds of change. Landscape is not just natural as sometimes it is suggested, but neither just humanly made as sometimes it is proposed. Both: natural and human are essential to the completeness of the actual entity. The interaction of the two factors: natural and human, the intensity of participation of each one of them in such interaction, and the many diverse ways in which the two interact, produce a wide range of tangible facts. The main issue is that the result is not just physical or quantitative, it is charged by attributes such as harmony, welcome, congruence, coherence, sound, or comprehensive related directly to human feelings. A sort of messages that the character of the place - the landscape - sends to the human beings starting a dialog that demands responses, those that most of the times are released unconsciously. In this way landscape becomes meaningful for their users: inhabitants or visitors who are, in other way of seeing it, part of the same local landscape. Thus, usually people dress and behave according to the natural and cultural frame were they move; it is difficult to imagine the desert with people other than that wearing large tunics walking beside their camels, or the Caribbean beaches without their fishermen or sea bather tourists. Less conspicuous but real is the significance of urban people image and behavior in different towns or villages, that contribute to the local landscape character.

Usually, visitors are more aware or conscious than locals of the landscape distinctive features; when they are good observers and willing to perceive, they discover the identity of the place mainly when the character differs from that of the places where they come from [3]. But undoubtedly the landscape perception, although unconscious, is more determinant for natives or even non-natives 
inhabitants, in building attachment and identity with the place and its landscape, even though it happens in diverse intensities or magnitudes of rootedness and belonging.

Values and feelings promote individual and collective behaviors that are expressed in the place [4], and constitute part of and contribute to shape the landscape of a place in a time. Those behaviors when they are strong enough to trace, transcend time and progressively accumulate defining a landscape local character. We can then talk about: identity of the place, the own physiognomy or character; identity with the place, the psychological relation and reaction of humans to the first, and identity for the place [5]; this last one representing the professional intervention conscious of its responsibility in guiding and follow up the landscape evolution.

\section{Natural bases}

Recognized or not, remembered or not, the base of our life and consequently the base of all kind of settlements, included the most contemporary advanced cities, is nature. Of course not the pristine environment that the planet earth showed thousands of years ago, but a strongly transformed one; nevertheless, a living nature, which manifests itself in persistent processes that technology frequently pretends to counteract in an insolvent manner. Although human kind has greatly impacted natural environment up to unsuspected levels, nature endures, demonstrating now and then its memory when claiming its territory.

Landscape ecology is concerned with spatial patterns and processes studied through the identification analysis and evaluation of the composition and functioning of matrix, patches and corridors, clearly present in wild areas where most of the time those components perform in balance.

From a different perspective, the disciplines in charge of shaping cities have generally ignored ecological values, relaying on the idea that nature is at the fringe and that when it comes into the urban thinking, it has to be artificially manipulated or hidden i.e. in pluvial straight and hard channels or sewages that quickly get rid of a great and useful resource that could counteract the unnecessary spending of treated water. The urban way to deal with pluvial water spreads even into suburban or rural areas. This is just an example of urban culture deviations that separate us of a sound understanding and dialogue with nature, and from enjoying a stimulant landscape.

"The cultural landscape is created from a natural landscape by a cultural group. Culture is the agent, nature is the environment, landscape culture is the result" UNESCO [6].

But where does the culture comes from? In a clear manner (Swanwick [7]), analyzes the influential cyclic relationship between place and people, people and place, shaping one to other continuously. It is a sort of spiral movement that expresses itself in a permanent evolving integral manifestation that sometimes demonstrate capacity to absorb changes or other times is overcome by the powerful impact of those. The result is the landscape character or personality that 
expresses identity and different degrees of belonging to the natural fundament that supports it, and without which it wouldn't exist.

Generally in Colombia, urban development has evolved from the supply of the natural environment, but little by little, gaining confidence, has done virtually wiping out the natural base, and has negatively altered the quality of its own environment. Several technics have been developed and efforts invested to compensate or replace natural functions artificially. There is a tendency to face and solve the effects, but there is not attention orientated to the main real causes, therefore the source of solutions -nature itself- is wasted.

\section{Split landscape}

When nature is not valuated unconscious cultural imposition comes. The introduction of values different to those that were present in these pre-Columbian lands more than five centuries ago at the encounter of the two worlds started the divorce between local nature and new beauty and use paradigms. The landscape was split up and the two main components, nature and culture, were not consequent, not directly connected, as they used to be. In relation with Western culture, Reboratti [8] states that implicitly or explicitly throughout its history the man was oblivious to nature, seeing it as a resource, as an enemy or as a distant equilibrium model. Instead, similarly to Eastern traditions, original local people tended to consider man and nature as a whole. It is one of the common traits to most indigenous ethnic groups, at least among the approximately 87 (DANE [14]) still surviving in Colombia. This thought is not as noticeable and influential as it should be, due to the short population of each ethnic group still alive, and also because of that this way of thinking difficultly transcend into cities due to the immediate economical profit that orientates the development.

At present in Colombia, urban development is repeatedly ignoring the underlying, surrounding and transversal nature that supports the city, so that undercutting reflects itself on a mistreated landscape. Certain recent efforts have been developed to counteract the tendency, but with the weakness of not counting with integral bases and not enough interdisciplinarity the results end up in loose parts.

The streams, to insist about one of the principal natural features in the urban realm, are progressively hidden and their positive or harmful power ignored. "However, urbanization clearly has a variety of interacting effects on stream ecosystems that may be further influenced by regional and historical differences in urban development and natural factors such as climate, physiography, geologic setting, vegetation, and soils" (Fitzpatrick [15]; Harding et al. [16]), [9]. Then nature is systemically organized, interdependent in its parts, where each one plays a proper role, and deserves attentive understanding and interchange.

As well, perhaps the most outstanding natural feature in cities is vegetation, and has a lot to do with the expression of local landscape character. Certain tree shapes are commonly considered "nice" because of their clean geometry near to that of artificial objects or because of their resemblance to manipulated materials. Those feelings reflect two ways of manpower: the dominium on physical things, 
and the understanding of the world almost exclusively through exact sciences, Euclidian geometry among others. Curiously, citizens who admire and enjoy geometrical shaped vegetation (natural or manipulated) within their urban environment strongly yearn for wild nature and search for the emotional and spiritual benefit of its contact during weekends or holydays. This demonstrates a mental splitting of the landscape idea that citizens usually bear in mind.

Figures 1 and 2 illustrate the environmental difference and sustainable input that could be derived from just a simple detail, framed in landscape concepts.

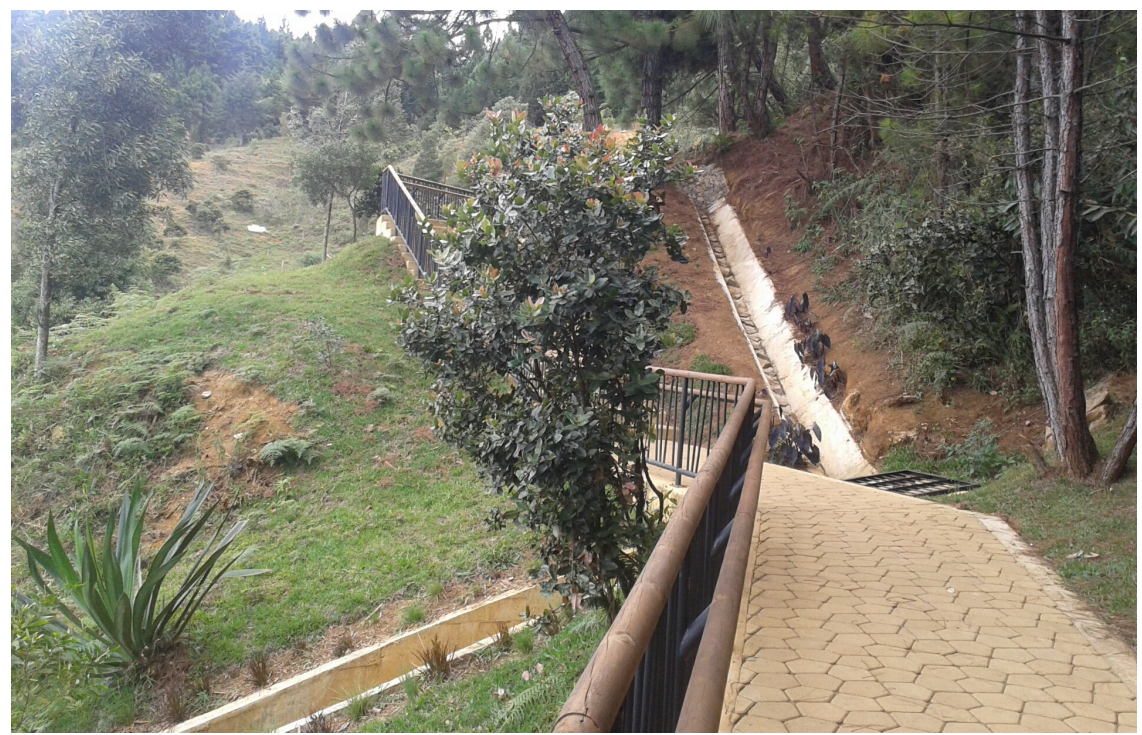

Figure 1: Separation of water from soil and vegetation (source: the author).

In the first case, the pyramidal shaped pines fragment the space, pedestrians and vehicles are exposed to sunshine and seeds and flowers attractive for micro fauna are absent diminishing biodiversity. In the second case the trees help to structure the space at human scale, offer welcoming (sense of place), intervisibility is improved as well as shade for pedestrians and vehicles; the habitat for singing birds and other manifestations of biodiversity represents an important contribution to the equilibrium in the big scale.

Another comparison is illustrated in figures 4 and 5. In the first, the manipulation of vegetal material as if it were inert, makes a great distance from natural successional evolution and the formal composition denies a sound partnership among diverse kinds of vegetation. The garden in figure 5 has been inspired in deep observation on vegetal natural behavior, reflects local identity, contributes to shape the space and therefore to the sense of place. It also demands less maintenance as a contribution to sustainability. The first simulates a collection of objects, the second a composition with a combined ecological and harmonious formal purpose. 


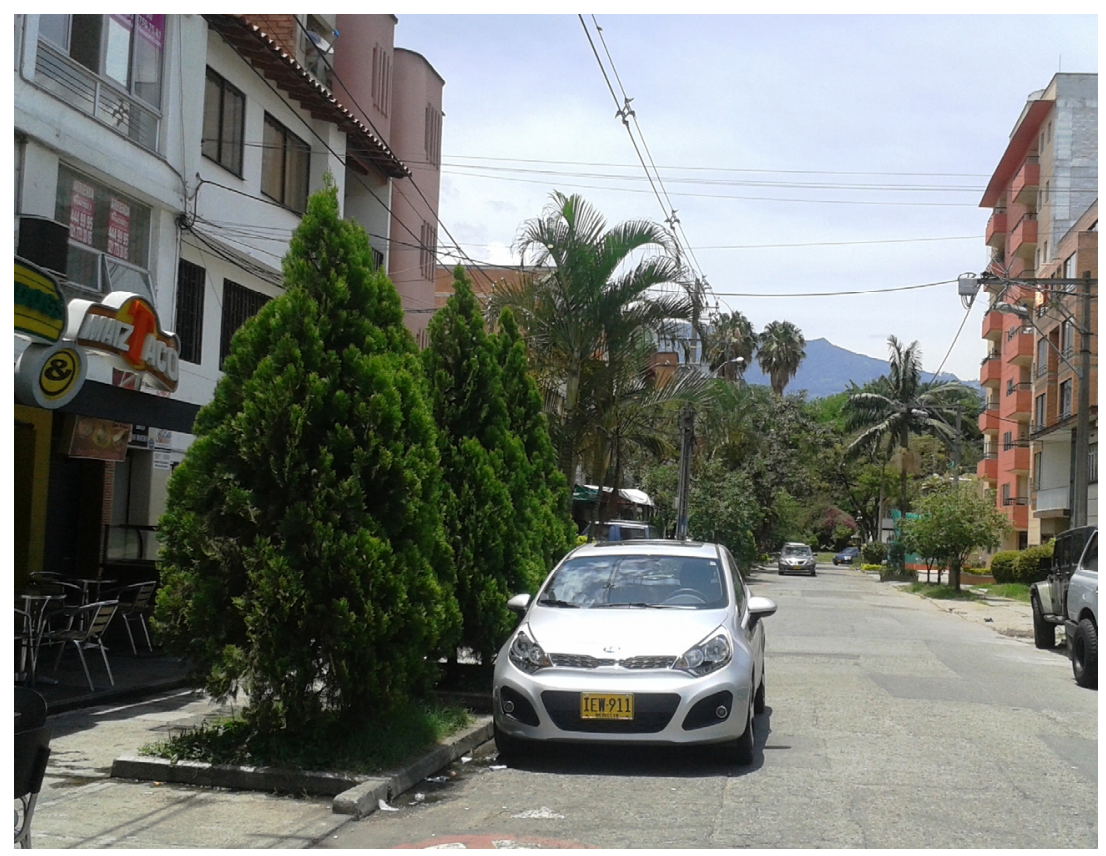

Figure 2: Natural geometrical shape of foreign vegetation in a Medellín neighborhood (source: the author).

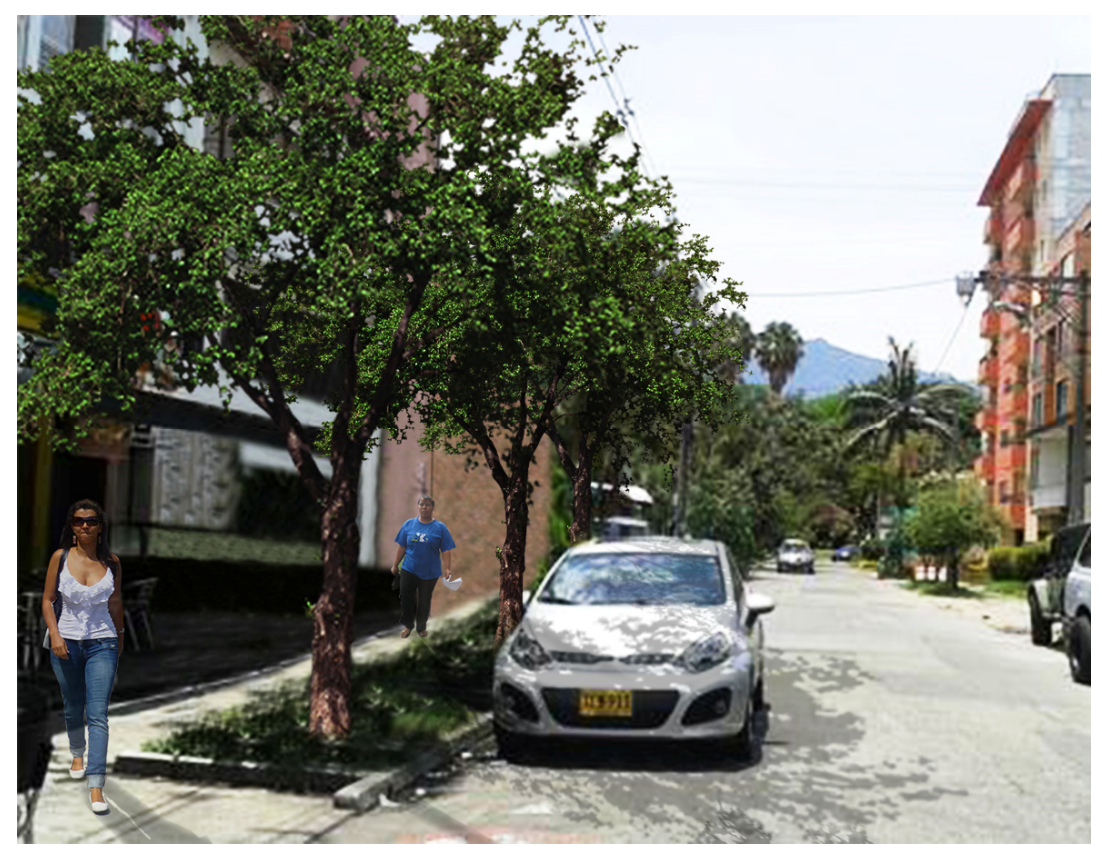

Figure 3: Native vegetation possibility (source: the author). 


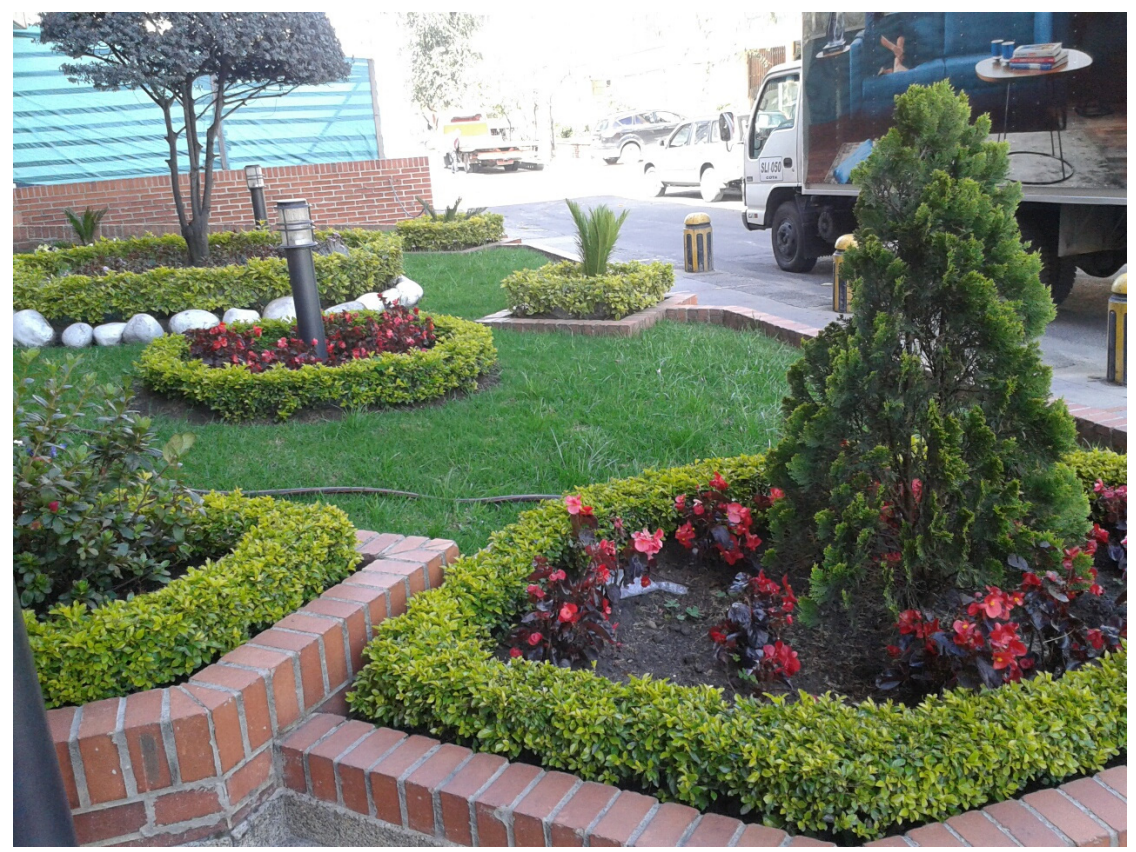

Figure 4: Geometrical shapes on foreign material in a public space in Bogotá (source: the author).

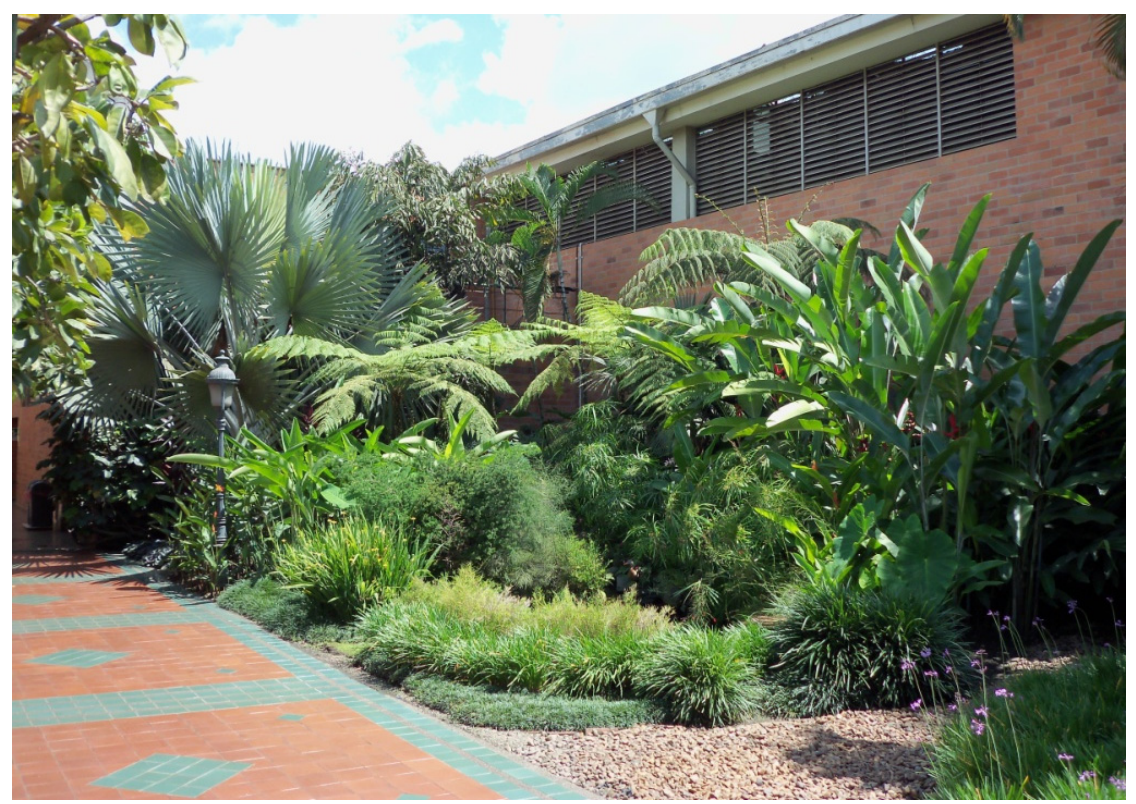

Figure 5: Composition inspired in local nature in an industry in Medellín (source: the author). 
These examples, in quite a small scale tend to demonstrate what Iverson Nassauer [10] expresses when she talks about a systemic integrity that gathers anthropocentric and ecocentric discourses, and also that those functionally sustainable landscapes happens - casually - to be seen as beautiful.

It is very important to clarify that the landscape disciplines are not reduced to gardens or vegetation. The previous are just examples, on minimal pieces, of concepts that must be backing the landscape structure or "green infrastructure" that should be present through the whole in all cities.

On the other hand, during decades the specialization of knowledge has driven to a series of wisdom kingdoms that guide narrowly focused actions and interventions, on a way far from a sustainable landscape and even farther from a true sustainable city. This knowledge splitting, together with other circumstances contributes to the generalized idea that nature is "there" or outside, and the city is "here".

As De las Rivas [11] points out: We sophisticate tools, but do not refine concepts or modify attitudes. This leads to a divorce between urban society and the natural processes, supported by the dangerous stunt of artificial comfort.

This phenomenon has been strengthened recently by commercial advertisement on all sorts of goods, and foreign models of internationalization inspired by other latitudes far from ours, where ecosystems are quite different, with much less biodiversity and consequently less resources.

The result of such tendency is the creation of what some authors call the "non-place" or non-landscape". Bigell and Chang [12], refer to Augé's explanation of how a non-place is characterized by its lack of community relation and says: The fact that globalization creates such non-landscapes is not surprising since the idea of a global community is largely an extrapolation; it is difficult to speak meaningfully of a global landscape. It implies that livable landscape has to be understood in a human scale, fitting of course in the planning scale of general conception.

The lack of attention to diverse interrelated scales when dealing with landscape represents a menacing circumstance, and urgent call for carefully local landscape assessment. This in order to achieve a truly recognition of the place and its resources, and also for identity oriented landscape management, that could stimulate belonging feelings for better behavior and living.

\section{Sustainable landscape}

Landscape is a continuous that gradually changes its character, both in space and in time, and although it is advisable to split it up into components for analysis and study, is not wise to transfer such a fragmentation into the physical reality. As Reboratti [8] says, talking about sustainable development: “...now more than ever...it is possible that the best contributions do not come from the 'heart' of disciplines but from their edges, those spaces where some lean out to the others".

Within the everyday language, sustainable is an adjective that accompanies more and more substantives. One wonders if it is an actual positioning of the concept or just a motivating fashion for a project or a product to be sold. 
Understanding the causes of this doubt, will allow a valuable contribution from the landscape point of view: to develop and reinforce a sense of wholeness and connectedness with the context and with wider scales of intervention and impact of small but repeated and coordinated actions.

Sustainable landscape means much more than environmental sustainability in small and big scale, it has to do with people, their perception, interpretation and attitudes towards their habitat. It has to cross natural, environmental, human and cultural layers in building a meaningful sense of place.

This task requires a worthy and advisable understanding of landscape in a systemic manner, opposite to the make-up status that has prevailed in many Colombian cities with emphasis in contemporary urban and suburban developments, as a tool among others, for commercial goals. In general, landscape architect, planners and designers, truly understand and share Selman [13] words: "...there is an acknowledgment of the need to 'people' landscapes not only through participatory processes, but more generally through wider reengagement between communities and places."

\section{Conclusions}

The landscape perspective and motivation proposes articulations instead of limits, systems instead of polygons - very common in planning issues - ecotones instead of frontiers. Those support a better recognizing of local nature, place and environmental benefits where to root policy, planning and action, for an honest sustainable urban development, belonging and better living.

"The need to incorporate landscape considerations into decision-making is not new, but has grown in importance as the emphasis on sustainable development has increased" says Swanwick [7]. Thirteen years later Colombian cities have very slowly started to apply this sane, advanced and promising recommendation. Better late than never, it is time to consolidate stages in that direction.

No wide or small scale urban, infrastructure, or physical development project should be undertaken without landscape considerations. There are many examples in North America and several European countries, where the landscape perspective is given a deserved status among the factors that intervene in urban, rural, sub-urban, industrial, infrastructural, or mining projects, as well as urbanrural borders management. Landscape contribution would help to a better insertion of interventions and dialog with the natural environment: structuring features, continuous processes and ecosystem dynamics, in order to guarantee a contribution to, if not enhancing, at least to the preservation of environmental conditions. This reverses in preventing instead of repairing, which should be the first principle of sustainability.

Some steps have been accomplished in Colombia, at Universidad Pontificia Bolivariana in Medellín in this sense:

- The establishment of the first Master Landscape Design program in the country. 
- A research on the landscape structural role of streams in the urban-rural border of Medellín

- The promotion of an Interagency Group of Landscape Study

- The first stages in the establishment of a Regional Landscape Observatory

As well, several tasks are to be undertaken within the scope directly related to sustainability and also in other focus of the landscape discipline such as culture, aesthetics, conservation and restoration. There is a wide field of research to be accomplished. First of all that concerned to local assessment on:

- The state of the art, of the practice on landscape matters in the nearby region.

- $\quad$ The present landscape character in diverse scales and situations.

- The local landscape evolution through the time.

- $\quad$ The lessons to be learnt from main mistakes and achievements.

Simultaneously, analysis of the incidence of landscape orientations in public policies, legislation and rules has to be undertaken, and consequently proposals have to be developed for the best way to incorporate this matter in environmental, planning and development legislation in all levels of governance.

Also efforts have to be invested in communication to diverse groups of people through formal and informal education in order to clarify the real scope and meaning of landscape matters as well as the significance of its awareness and consequent related actions.

\section{References}

[1] Jellicoe G., and S., The landscape of man, shaping the environment from prehistory to the present day. Thames and Hudson Ltd, London 1982.

[2] Latin American Landscape Initiative - LALI - http://lali-iniciativa.com/ que-es-lali/

[3] Hernandez, B., Hidalgo, M.C., Salazar-Laplace M.E., Hess S., Place attachment and place identity in natives and non-natives. Journal of Environmental Psychology, (27), pp. 310-319, 2007.

[4] Canter D., Psicología de lugar. Editorial Concepto, México 1987.

[5] Aponte, G., Paisaje e identidad cultural. Tabula Rasa 21(1), pp. 153-164, Bogotá 2003.

[6] UNESCO, CCBP, Programa de desarrollo de capacidades para el Caribe. www.whc.unesco.org/document/106130.

[7] Swanwick, C. and Land Use Consultants, Landscape Character Assessment: Guidance for England and Scotland CAX 84, Countryside Agency, Cheltenham and Scottish Natural Heritage, Edinburgh 2002.

[8] Reboratti, C., Ambiente y sociedad: conceptos relacionales. Buenos Aires, Ariel 2000.

[9] Brown L. R., Gray R. H., Hughes R. M., Meador M. R., Introduction to Effects of Urbanization on Stream Ecosystems. American Fisheries Society Symposium 47 pp. 1-8, 2005. 
[10] Iverson Nassauer, J., Cultural sustainability: aligning aesthetics and ecology, Placing nature: Culture and landscape ecology, pp. 65-84.

[11] De las Rivas J.L., Hacia una ciudad paisaje. Urban Polired UPM, pp. 7993, 2013.

[12] Bigell, W., Chang, C., The Meanings of Landscape: Historical Development, Cultural Frames, Linguistic Variation, and Antonyms, ECOZON@5(1),pp. 84-103, 2014.

[13] Selman P., What do we mean by sustainable landscape? Sustainability: Science, Practice, 6 Policy http://ejournal.nbii.org pp. 23-28, 2008.

[14] DANE (Departamento Administrativo Nacional de Estadística. Colombia una nación multicultural. Su diversidad étnica, 49 p., 2007.

[15] Fitzpatrick F.A. Changes in Aquatic Habitat and Geomorphic Response to Urbanization, with Implications for Assessing Habitat Degradation, 24 p., Winsconsin Water Science Center, 2005.

[16] Harding et al. Stream biodiversity: the ghost of land use past. Proceedings of the National Academy of Sciences. Ecology Vol 95: pp. 14843-14847. December 1998. 